\title{
Large differences in catch per unit of effort between two minnow trap models
}

\author{
Juha Merilä ${ }^{*}$, Hanna-Kaisa Lakka ${ }^{2}$ and Antti Eloranta ${ }^{3}$
}

\begin{abstract}
Background: Little is known about variation in catch per unit of effort (CPUE) in stickleback fisheries, or the factors explaining this variation. We investigated how nine-spined stickleback (Pungitius pungitius) CPUE was influenced by trap model by comparing the CPUEs of two very similar minnow trap models fished side-by-side in a paired experimental design.

Results: The galvanized trap type (mean CPUE $=1.31 \mathrm{fish}^{-1}$ ) out-fished the black trap type (mean CPUE $=0.20$ fish $\mathrm{h}^{-1}$ ) consistently, and yielded on average $81 \%$ more fish.

Conclusions: The results demonstrate that small differences in trap appearance can have large impacts on CPUE. This has implications for studies designed to investigate abundance and occurrence of fish using minnow traps.
\end{abstract}

Keywords: Fishery, Trap, Catchability, CPUE, Pungitius pungitius, Stickleback, Funnel trap

\section{Background}

Catch per unit of effort (CPUE) is an important variable in fisheries sciences, as it provides means to monitor population size trends (e.g. [1]), relative abundance of species in different habitats and sites (e.g. [2]), as well as to compare efficiency of different fishing gear [3-5]. It is well established that CPUE can be influenced by various environmental factors [6-10], show profound seasonal variation [11] and be sensitive to the type of fishing gear used [4,5,12,13]. For instance, Guy et al. [3] compared CPUE for white crappies (Pomoxis annularis) as estimated from gill and trap nets, and found little correspondence between the estimates obtained with different gear across different reservoirs and years.

Understandably, factors influencing the CPUE have been mainly studied in species of commercial interest. Less effort has been put towards studying factors that influence CPUE in species such as sticklebacks (Gasterostidae), which are popular models for ecological and evolutionary biology research (e.g. $[14,15])$ yet hold little or no commercial interest. Recently, influence of trap type and use of bait on CPUE of nine-spined sticklebacks (Pungitius pungitius) was investigated [16], and clear trap type and bait effects

\footnotetext{
* Correspondence: juha.merila@helsinki.fi

${ }^{1}$ Ecological Genetics Research Unit, Department of Biosciences, University of Helsinki, 00014, Helsinki, Finland

Full list of author information is available at the end of the article
}

were revealed. However, the above mentioned study is thus far the only quantitative study focused on factors influencing CPUE in sticklebacks, and was restricted to two collapsible trap types.

The aim of this study was to test whether two commonly used and superficially similar metallic minnow trap types differ in their CPUE when catching ninespined sticklebacks.

\section{Methods}

The trapping was conducted in Rytilampi (ca. 66 $23^{\prime} 07^{\prime \prime}$ $\mathrm{N}, 29^{\circ} 18^{\prime} 42^{\prime \prime} \mathrm{E}$ ), which is an isolated pond (surface area = $4.98 \mathrm{ha}$ ) with maximum depth of ca. $5.1 \mathrm{~m}$. The two different minnow trap types, both manufactured by Frabill (Jackson, Wisconsin, USA) are pictured in Figure 1. One of the trap types was a galvanized funnel shaped trap (also known as GEE Minnow trap) measuring $419 \mathrm{~mm} \times$ $229 \mathrm{~mm}$ (model \# 1279), henceforth referred to as the silver trap. The other trap type (model \# 1271) was similar to the silver trap in its dimensions, but had a black vinyl coating (Figure 1a), and is henceforth referred to as the black trap. Moreover, while the netting in the silver trap is square-shaped, that of the back trap is diamond-shape (Figure 1a). Both trap types have two round entrances (ca. $25 \mathrm{~mm}$ in diameter; Figure $1 \mathrm{~b}$ ) and are widely used by researchers (e.g. $[7,17]$ ) and fishermen (see Discussion). All traps were set unbaited. 


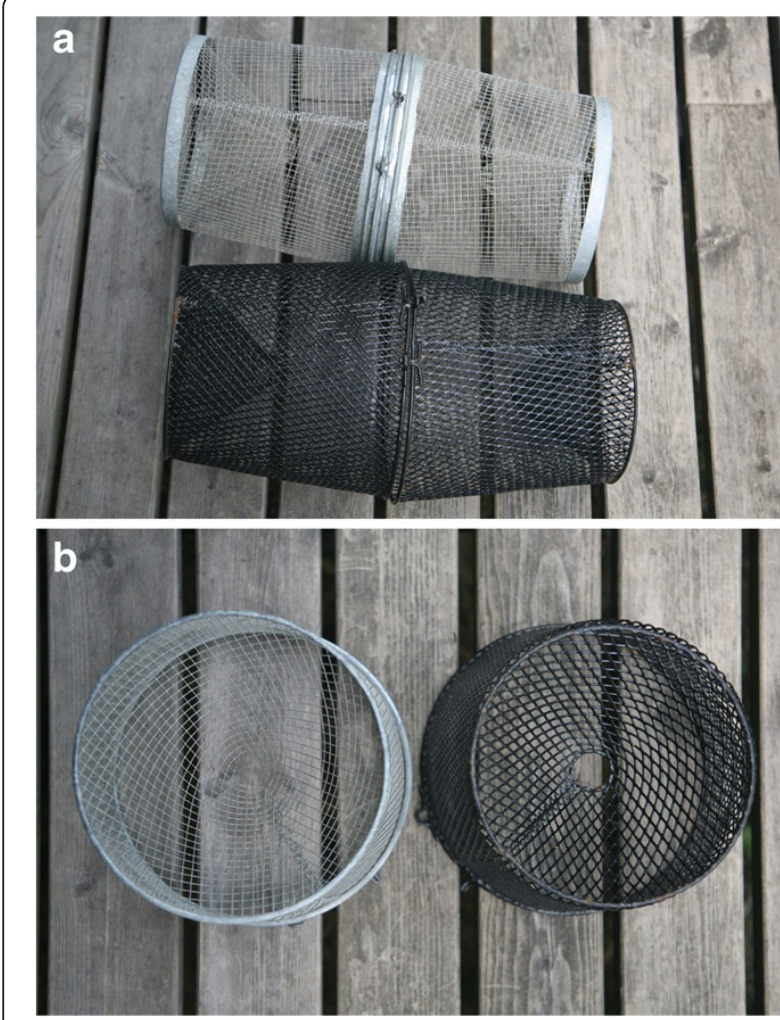

Figure 1 The two minnow trap types used. (a) View from above and (b) from trap entrance.

Set 1: Six pairs of traps, each consisting of one silver and one black trap, were set on July 72012 between 20.00-20.30, and retrieved July 82012 between 13.0014.00. This corresponds to an average soak time of $16.6 \mathrm{~h}$ (range: 16.4-16.7) and 199 trap-hours (=12 traps $\times 16.6 \mathrm{~h}$ ). The traps were lowered to the bottom in a pairwise fashion at depths ranging from $2-3.8 \mathrm{~m}$, and their distance from shore ranged between 5 and $50 \mathrm{~m}$. When the traps were retrieved, the number of ninespined sticklebacks in each trap was counted and recorded. Water temperature during the trapping was about $18^{\circ} \mathrm{C}$ at a depth of $10 \mathrm{~cm}$ from the surface.

Set 2: A second set, also consisting of six pairs of traps, was set on July 102012 between 06.15-06.35, and retrieved July 11 between 06.20-06.35. This corresponds to an average soak time of $24.0 \mathrm{~h}$ (range: 23.9-24.3) and 288 trap-hours. Setting was done otherwise in a similar fashion as in Set 1, but the traps were fished from the shore at depths between $0.6-1 \mathrm{~m}$. The trap pairs in this set were located 5-50 $\mathrm{m}$ apart from each other.

The CPUE for a given trap was estimated as the number of fish caught divided by trap-specific soak time, yielding an estimate of number of fish caught per hour.

The data was analyzed using a generalized linear mixed model (GLMM) in which the number of fish caught was treated as Poisson distributed response variable, and the trap type and set (i.e. the two catching occasions) as factors. This analysis was supplemented with two non-parametric univariate tests suited for analyzing data of matched-pair nature. First, a Wilcoxon Signed Rank test was used to test whether there was a difference in CPUE between paired silver and black traps. Second, a more conservative sign test was used to the same effect. Two-tailed tests were used. All analyses were conducted using JMP statistical software (ver. 9.0.0; SAS Institute Inc.) with an Apple Macintosh platform.

\section{Data accessibility}

All the data is given in Table 1.

\section{Ethics statement}

The work described in this paper does not constitute an animal experiment in legal sense, and hence, the only required permissions were national personal fishing licenses for 2012 (possessed by all authors) and a license (\# 3087/41/2011) from Metsähallitus, owner of the water body where the fishing was done.

\section{Results}

A total of 317 fish were caught, of which 276 were from silver traps and 41 from black traps (Table 1). GLMM showed that the number of fish caught differed significantly between trap types $\left(\chi^{2}=140.12, P<0.001\right)$ and the two sets $\left(\chi^{2}=98.09, P<0.001\right.$; Figure 1$)$. Also, the traptype ${ }^{*}$ set interaction was significant $\left(\chi^{2}=6.04, P=0.014\right)$, showing that the difference between trap types was less pronounced in the second as compared to the first set (Figure 2).

Table 1 Number of nine-spined sticklebacks caught in each of the traps in the two sets

\begin{tabular}{cccc}
\hline & & \multicolumn{2}{c}{ Number of fish } \\
\cline { 2 - 4 } Set & Trap-pair & Silver trap & Black trap \\
\hline 1 & 1 & 46 & 2 \\
1 & 2 & 43 & 17 \\
1 & 3 & 32 & 5 \\
1 & 4 & 47 & 0 \\
1 & 5 & 24 & 8 \\
1 & 6 & 33 & 7 \\
2 & 7 & 7 & 1 \\
2 & 8 & 4 & 0 \\
2 & 9 & 7 & 0 \\
2 & 10 & 16 & 0 \\
2 & 11 & 11 & 0 \\
2 & 12 & 6 & 1 \\
\hline
\end{tabular}




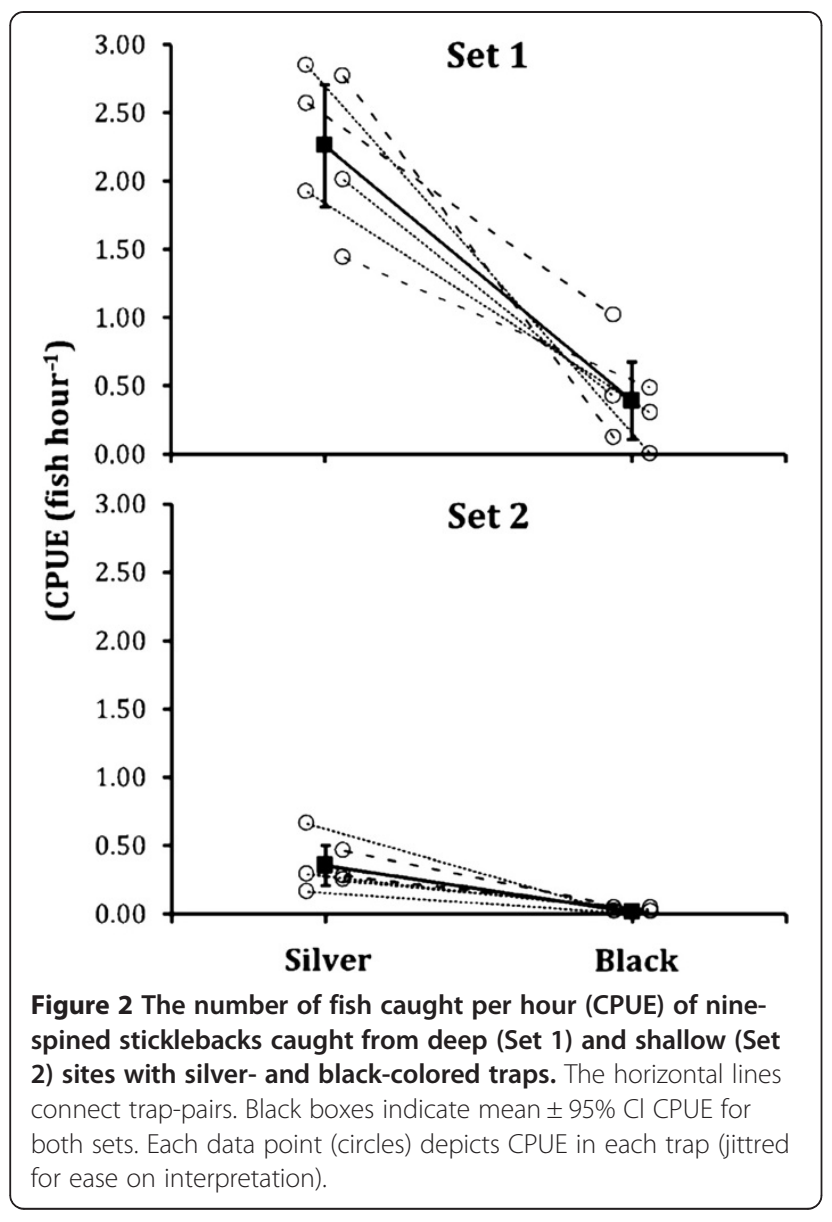

Wilcoxon Signed Rank test confirmed the GLMM results: CPUE in silver traps (mean \pm S.E. $=1.31 \pm 0.31)$ was significantly (on average 6.5 times) larger than in black traps (mean \pm S.E $=0.20 \pm 0.09 ; \quad S=-39.00, \quad P=0.0005$ ). The same conclusion was reinforced by the sign test $(M=-6.00, P=0.0005)$.

\section{Discussion}

The results of this study clearly demonstrate that the silver traps out-fished the black traps, with a large margin. This was not entirely unexpected, as earlier experiences in trapping three-spined sticklebacks (Gasterosteus aculeatus) with these same traps in northern Finland have left an (unquantified) impression that the silver traps are more effective than the black traps. Similar testimonies are also available from North America: several customer reviews (www.cabelas.com) of these traps state that silver traps catch more minnows, shiners and crawfish than black traps (e.g. Anonymous, March 10 2010: "Side by side, I'll have two-three times more minnows in the galvanized trap vs. black coated trap"; Chrisfromiowa, July 3 2007: “...side by side the black traps against the steel and steel always pull in more bait"). Hence, the better catch rate of silver over black traps appears to be a general - albeit as yet poorly quantified - phenomenon across different target species, habitats and geographic localities.

Why do the silver traps catch more fish than the black traps? One possible explanation is that the shiny appearance of the silver traps attracts fish for some reason, or that fish caught within silver traps escape (cf. [18]) less frequently than fish caught within black traps. Another possibility is that the dark and shadier appearance of the black traps repels fish. In fact, although the basic dimensions of the two trap types are the same, the vinyl coating of the black traps, in combination with their diamond shaped meshing, renders the black traps more "closed" and shady (Figure 1). This might influence the entry and/or retention rate of fish, and thereby also catchability. Differences in catchability of square and diamond shaped meshing have earlier been reported in the context of pelagic herring (Clupea harengus) trawling [19].

Attraction by conspecifics might also play a role in the marked difference in the CPUE performance between trap types. If fish within silver traps are more visible to conspecific than fish in black traps, this might increase the catchability of the silver traps. Naturally, the electrochemical characteristics of the two trap types are also likely to differ, but the significance that this might bear on catches remains to be investigated. Whatever the reason for the difference, it is an undisputed fact that silver traps outperform black traps in catching nine-spined sticklebacks, and possibly, also many other species of fish.

We observed that the CPUE for both trap types was markedly different between the two sets. This difference can owe to various factors, including differences in trapping location, depth, temperature and weather conditions among the two sets. Also the shorter soak time of the first as compared to second set might explain the higher CPUE in the first set (cf. [20]). Yet, in spite of these differences, the relative performance of the trap types remained the same, suggesting that the trap type rather than other circumstances may be more important determinants of the CPUE. However, as habitat complexity and predation risk are known to influence minnow trap catches [17], further experiments in different contexts (e.g. in turbid water or under predation risk) are needed to evaluate whether the results of this study can be generalized to other contexts too.

It is well established that heterogeneity in fishing methods and gear can create heterogeneity and even bias in studies seeking to estimate abundance or even distribution of particular fish species (e.g. [4,5,12,13]). Our finding that trap-type can have a large impact on CPUE of nine-spined sticklebacks adds to this evidence, and has implications for studies aiming to establish 
occurrence and abundance of fishes. For instance, efforts have been undertaken to map the presence or absence of nine-spined sticklebacks in large number of small lakes and ponds in Finland using foldable minnow traps [16]. In most cases presence of the species could not be established, but the surveys used trap types which were estimated to yield CPUEs in order of 0.23 fish $\mathrm{h}^{-1}$ in the same pond as used in this study [16]. This value corresponds quite well with the value obtained for "black" traps in the present study (0.20), suggesting that the surveys might have easily overlooked presence of ninespined sticklebacks in low-density locations. Hence, together with earlier results, the results emphasize the need for careful selection and standardization of fishing gear in both quantitative (i.e. abundance) and qualitative (i.e. distribution) studies.

\section{Conclusions}

In practical terms, the results of this study deliver at least two clear messages for researchers wanting to catch sticklebacks. First, the silver traps are likely to yield better catches than the black traps. Second, if different types of traps are used, it will be important to control for variation in CPUE due to trap type. In the future, studies focusing on behavioral mechanisms underlying differences in catchability by different trap types could provide interesting insights on fundamental biological questions about factors influencing animal decision making.

\section{Competing interests}

The authors declare that they have no competing interests.

\section{Authors' contributions}

JM conceived the study. JM, AE, H-KL carried out the field work. JM analyzed the data. JM, AE, H-KL all contributed to writing the manuscript. All authors read and approved the final manuscript.

\section{Acknowledgements}

We thank Mari Siivonen for help with fieldwork, Marika Lilja for logistic support, Jacquelin De Faveri for comments on earlier version of this manuscript.

\section{Author details}

${ }^{1}$ Ecological Genetics Research Unit, Department of Biosciences, University of Helsinki, 00014, Helsinki, Finland. ${ }^{2}$ Department of Environmental Sciences, University of Helsinki, 15140, Lahti, Finland. ${ }^{3}$ Department of Biological and Environmental Sciences, University of Jyväskylä, 40014, Jyväskylä, Finland.

Received: 21 February 2013 Accepted: 10 April 2013

Published: 16 April 2013

\section{References}

1. Kidd K, Blanchfield PJ, Mills KH, Palace VP, Evans RE, Lazorchak JM, Flick RM: Collapse of a fish population after exposure to a synthetic estrogen. Proc Natl Acad Sci USA 2007, 104:8897-8901.

2. Gryska AD, Huberta WA, Gerowb KG: Relative abundance and lengths of Kendall Warm Springs Dace captured from different habitats in a specially designed trap. Trans Am Fish Soc 1998, 127:309-315.

3. Guy CS, Willis DW, Schultz RD: Comparison of catch per unit effort and size structure of white crappies collected with trap nets and gill nets. N Am J Fish Manage 1996, 16:947-951.
4. Atar HH, Olmez M, Beckan S, Secer S: Comparison of three different traps for catching blue crab (Callinetes sapidus Rethbn 1896) in Beymelek Lagoon. Turkish J Vet Anim Sci 2002, 26:1145-1150.

5. Hanchin PA, Willis DA, Sauverb TR: Comparison of concurrent trap-net and gill-net samples for Black Bullheads. J Freshw Ecol 2002, 17:233-237.

6. Stott B: Some factors affecting the catching power of unbaited fish traps. J Fish Biol 1970, 2:15-22.

7. Blaustein L: Effects of various factors on the efficiency of minnow traps to sample mosquitofish (Gambusia affinis) and green sunfish (Lepomis cyanellus) populations. J Am Mosq Contr Assoc 1989, 5:29-35.

8. He X, Lodge DM: Using minnow traps to estimate fish population size: the importance of spatial distribution and relative species abundance. Hydrobiologia 1990, 190:9-14.

9. Bigelow KA, Boggs $\mathrm{CH}$, He X: Environmental effects on swordfish and blue shark catch rates in the US North Pacific longline fishery. Fish Oceanogr 1990, 8:178-198.

10. Lindquist DC, Shaw RF: Effects of current speed and turbidity on stationary light-trap catches of larval and juvenile fishes. Fish Bull 2005, 103:438-444.

11. Cross TK, Mclnerry MC, Schupp DH: Seasonal variation in trap-net catches of bluegill on Minnesota lakes. North Am J Fish Manag 1995, 15:328-389.

12. Jackson DA, Harvey $\mathrm{HH}$ : Qualitative and quantitative sampling of lake fish communities. Can J Fish Aquat Sci 1997, 54:2807-2813.

13. Layman CA, Smith DE: Sampling bias of minnow traps in shallow aquatic habitats on the eastern shore of Virginia. Wetlands 2001, 21:145-154.

14. Bell MA, Foster S: The Evolutionary Biology of the Threespine Stickleback. Oxford: Oxford University Press; 1994.

15. Östlund-Nilsson S, Mayer I, Huntingford FA: Biology of the Three-spined Stickleback. Boca Raton: CRC Press; 2007.

16. Merilä J: Factors influencing nine-spined stickleback (Pungitius pungitius) trapping success. Ann Zool Fennici 2012, 49:350-354.

17. Dupuch A, Paradis Y, Magnan P: Behavioural responses of prey fishes to habitat complexity and predation risk induce bias in minnow trap catches. J Fish Biol 2011, 79:533-538.

18. Culp NE, Glozier JM: Experimental evaluation of a minnow trap for small lotic fish. Hydrobiologia 1989, 175:83-87.

19. Suuronen P, Millar RB: Size selectivity of diamond and square mesh codends in pelagic herring trawls: Only small herring will notice the difference. Can J Fish Aquat Sci 1992, 49:2104-2117.

20. Kneib RT, Craig AH: Efficacy of minnow traps for sampling mummichogs in tidal marshes. Estuaries 2001, 24:884-893.

doi:10.1186/1756-0500-6-151

Cite this article as: Merilä et al:: Large differences in catch per unit of effort between two minnow trap models. BMC Research Notes 2013 6:151.

\section{Submit your next manuscript to BioMed Central and take full advantage of:}

- Convenient online submission

- Thorough peer review

- No space constraints or color figure charges

- Immediate publication on acceptance

- Inclusion in PubMed, CAS, Scopus and Google Scholar

- Research which is freely available for redistribution 